\title{
GUERRA E PAZ: HENRIQUE V E O MODELO DE CONDUTA DO IMPERADOR NA GESTA FRIDERICI I. IMPERATORIS DE OTTO DE FREISING.
}

\section{Lukas Gabriel Grzybowski ${ }^{1}$}

O espaço reservado na Gesta de Otto de Freising para narrar o reinado de Henrique $\mathrm{V}$ resume-se a apenas cinco capítulos dentro do livro primeiro da Gesta Friderici, dos quais dois tratam dos feitos do sobrinho do imperador, o duque Frederico II da Suábia. A nossa proposta neste trecho ficará então dividida em dois grandes eixos. $\mathrm{O}$ que o cronista escreve a respeito do imperador, e o que escreve do duque suabo. Adiantamos já de partida que são modelos antagônicos, e desempenham um papel fundamental na construção da obra do frisigense ${ }^{2}$.

Logo no início da sua narrativa a respeito do reinado de Henrique V, Otto de Freising aponta o vigor e a fortitude do imperador, que submeteu todo o Império ao seu comando. "Hic [Henrique V] armis strennuissimus totum imperium ita in brevi suae subiecit ditioni [...] Quot ergo quanta tam Romae quam in Italia fortia gesserit..." (OTTO in: WAITZ: 1912, p. 26). Entretanto, na seqüência da narrativa o bispo mostra que o imperador não fazia bom uso de suas virtudes, como no caso do cerco a Mouzon, e que esta postura levava, segundo o cronista, à ruína do Império. A construção do bispo apresenta um imperador implacável, que faz a guerra de maneira inesperada, e subentende-se, injusta. A falta de justificativa para as suas ações, dentro da perspectiva providencialista característica da crônica cristã medieval, leva ao fracasso da

Mestrando em História no Programa de pós-graduação em História da Universidade Federal do Paraná, vinculado à linha de pesquisa Cultura e Poder e ao NEMED (Núcleo de Estudos Mediterrânicos), sob a orientação da Prof. ${ }^{a}$ Dr. ${ }^{a}$ Fátima Regina Fernandes, e com o apoio da CAPES (Coordenação de Aperfeiçoamento de Pessoal de Nível Superior).

${ }^{2}$ Chamamos de frisigense o bispo Otto de Freising com base no genitivo latino atribuído ao mesmo dentro da edição da MGH frisigensis. 
campanha imperial no cerco de Mouzon, "si bien parece que el autor rehúye deliberadamente insistir en la idea [...] de uma Providencia totalmente dominadora de la historia..." (GALAN SANCHEZ: 1994, p. 48). O furor de Henrique V era a única justificativa para a guerra, o que, portanto, não a colocava dentro de uma perspectiva cristã de guerra justa, já presente naquele momento pela presença de um ideal cruzadístico.

$\mathrm{O}$ abuso de sua fortitudo faz com que Henrique $\mathrm{V}$ abandone o modelo ideal de imperador, pois com isso o rei afasta-se da temperantia. Esse afastamento fica evidente quando o cronista afirma que "Qua de re inflammatus princeps predictum comitem ad patibulum trahi iussit", e mais adiante quando afirma que o imperador "turbato pre ira oculo" (OTTO in: WAITZ: 1912, p. 27). Essa atitude, segundo Otto, se deu, pois o imperador foi dominado pela ira, um dos pecados condenados pela fé cristã, ira a qual inquietava a pax imperial.

A relação entre o imperador e a sociedade política, na Alta Idade Média, refletia-se nas relações de vassalidade que o feudalismo implantara. Elas estavam ligadas pela fides e eram legitimadas pela iustitia. O que o trecho apresenta de forma mais generalizada é que, em última instância, quando as relações de poder dentro da sociedade política imperial são guiadas pelas virtudes cristãs, o resultado político dessas relações tende à pax. Isso podemos afirmar tendo em mente que no momento em que Henrique $\mathrm{V}$ abandona suas virtudes e age "cegado pela ira" e com o espírito "inflamado" o Império encontrou a guerra.

O cronista segue em sua narrativa escrevendo sobre $o$ casamento de Henrique V e Matilda da Inglaterra, apontando que no momento em que este casamento acontece, um grande cisma divide o Império entre seus príncipes. É a partir desse ponto que a narrativa começa a centrar-se na figura do duque Frederico II da Suábia. Sobre o duque, Otto escreve que foi o único príncipe a não rebelar-se contra o imperador. 
A maneira como o cronista constrói sua estrutura narrativa até chegar a este ponto é bastante significativa. Primeiramente o relato do esforço bélico do imperador para subjugar todo o território imperial, em seguida o relato de seu fracasso no episódio do cerco de Mouzon, ligado ao mal uso de suas virtudes e só então a ênfase na rebelião dos príncipes e o cisma interno do Império. O que o bispo está propondo com esta estrutura é que a rebelião dos nobres germânicos não era um problema a priori no reinado de Henrique $\mathrm{V}$, mas que pelos abusos de seu poder, o imperador acabou atraindo para si o desfavor divino, refletido na oposição que este encontrava para governar o Império. Pela sua postura agressiva para com os príncipes germânicos o imperador ao mesmo tempo se afasta do modelo ideal das virtudes e encontra cada vez mais oposição dentro dos seus domínios.

Podemos encontrar reforço para tal argumento dentro da própria narrativa do frisigense, quando na seqüência de sua Gesta ele apresenta o contra-modelo dos fracassos imperiais na figura do duque Frederico II da Suábia. Essa distinção é bastante marcada na obra do bispo e aponta para o caráter providencial do reinado de Frederico Barbarossa ${ }^{3}$, colocando-o como o coroar de todo um processo de translatio imperii das mãos de imperadores degenerados para os virtuosos Hohenstaufen da Suábia.

Analisemos inicialmente o trecho no qual o cronista apresenta o personagem do qual passará a narrar os feitos, Frederico II da Suábia. "Quot et quanta ergo Fridericus Suevorum dux nobilissimus vel imperatore presente vel in Italia morante stilo digna tunc gesserit, quia in multorum adhuc habentur memória, summatim dicemus" (OTTO in: WAITZ: 1912, p. 27-28). Traçando um paralelo com a apresentação que o bispo faz de Henrique V "Quot ergo et quanta tam Romae quam in Itália fortia gesserit, quia in priori dicta

${ }^{3}$ Lembrando que o ápice da narrativa do frisigense na Gesta é o reinado de Frederico, comitente e personagem principal do relato do bispo. Embora estejamos analisando um trecho curto e bastante específico dessa Gesta, não podemos perder de vista seu quadro geral, sob pena de incorrer em erros da análise. 
sunt hystoria, supersedemus" (OTTO in: WAITZ: 1912, p. 26), notamos a deliberada utilização da mesma estrutura narrativa, indicando uma intenção comparativa entre as atuações dessas duas personagens. A partir dessa apresentação o frisigense constrói a narrativa dos feitos de Frederico II como contraposição a Henrique $\mathrm{V}$, escolhendo cuidadosamente os fatos de modo a mostrar as atuações antagônicas de ambos, localizando no suabo o seu modelo ideal. Por isso vemos que, assim como no caso do imperador, o relato acerca do duque apresenta três episódios principais, em paralelo com aqueles de Henrique V: a submissão dos senhores de seus territórios - neste caso o ducado da Suábia; um cerco, à cidade de Mainz; e seu casamento com Judith, filha de Henrique, o Negro, da Baviera.

Iniciemos então com a narrativa do frisigense a respeito da maneira como o duque extende seu poder por todo o território no qual é investido. O cronista escreve que "Ipse enim de Alemannia in Galliam transmisso Rheno se recipiens totam provinciam a Basilea usque Maguntiam, ubi maxima vis regni esse noscitur, paulatim ad suam inclinavit voluntatem" (OTTO in: WAITZ: 1912, p. 28). Vemos aqui que o bispo apresenta um panorama bastante distinto entre o modo como o duque suabo e o imperador Henrique $\mathrm{V}$ procederam para serem reconhecidos em seus domínios. Enquanto este se impôs pela guerra e violência, aquele por seu prestígio, como fica evidente em "Erat autem predictus dux in bellis fortis, in negotiis ingeniosus, vultu et animo serenus, in sermone urbanus donisque tam largus, ut ob hoc multitudo maxima militum ad eum conflueret seque ad serviendum illi ultro offerret" (OTTO in: WAITZ: 1912, p. 28). Aqui retornamos ao tema das virtudes cristãs. Otto explicita o fato do sucesso de Frederico II estar diretamente ligado às suas virtudes, de maneira que nos repetimos em apontar para o caráter duplo que Otto atribui às virtudes, dentro de uma perspectiva pública e cristã.

É importante ressaltar que o bispo de Freising identifica Frederico com a mesma virtude que Henrique V, a fortitudo. Entretanto, enquanto no imperador ela é descontrolada, levando-o ao 
pecado da ira, no duque ela é equilibrada pelo 'espírito sereno' e suas outras virtudes. É a combinação das virtudes que tornam Frederico II hábil na política, tanto na guerra quanto na paz, e garantem que o duque exerça plenamente seu poder sobre a Suábia. Muito além de apenas extender seu poder, entretanto, a política do Hohenstaufen faz com que os senhores e cavaleiros suábos busquem voluntariamente o favor de Frederico, o Caolho ${ }^{4}$. A construção do cronista aponta para o fato de que, enquanto o imperador, modelo de degeneração, encontra constantes dificuldades para governar e controlar os príncipes imperiais, com os quais tem que constantemente guerrear devido à sua insubmissão, o duque suabo, ideal, atrai seguidores, fortalecendo cada vez mais sua posição diante da Suábia e do Império.

Seguindo a narrativa vamos ao segundo ponto no qual observamos uma oposição entre a atuação de Frederico II, o Caolho, e Henrique V. Trata-se do episódio do cerco de Mainz pelo duque suabo, que se opõe ao já analisado cerco a Mouzon de Henrique V. O frisigense escreve:

Igitur omnibus circa Rhenum, ut supra dictum est ad nutum suum inclinatis, Maguntio archiepiscopo Alberto, omnium allius temporis regni principum versutissimo et locupletissimo, eo quod predictae factionis caput et auctor fuerat, bellum indixit vastatisque cunctis in circuitu, tandem ipsamcivitatem cum infinita multitudine militum ac plebis obsidione cinxit. (OTTO in: WAITZ: 1912, p. 28).

Evidencia-se aqui em primeiro lugar o fato do cronista apontar a guerra de Frederico II como uma guerra justa. Podemos chegar a tal conclusão pois o bispo escreve que o duque suabo se lançou no conflito para combater o 'principal líder da rebelião contra o imperador', fato que vai de encontro com o papel atribuido por Henrique IV aos Staufer da Suábia, que era combater os inimigos do Império. ${ }^{5}$ Em segundo lugar é importante notar que o Caolho se

\footnotetext{
${ }^{4}$ Epíteto conseguido após a perda de um olho, provavelmente em batalha em meio às lutas contra Lotário III.

${ }^{5}$ Cf. OTTO in: WAITZ: 1912. Lib. I, cap. 8.
} 
lança na guerra após alcançar o apoio de todos os senhores da região do Reno, exercendo seu domínio sobre estes 'da forma como anteriormente citamos', o que se opõe à narração do cerco realizado por Henrique V, que além de ser injustificado - como já vimos, o cronista indica que o imperador supreendeu a todos com tal atitude é precedido pelo temor - e não apoio - dos povos da Gália. ${ }^{6} \mathrm{~A}$ presença dessa construção na Gesta aponta para a virtude da prudentia. Ao contrário de Henrique V, Frederico II mostra cautela ao fazer guerra contra o arcebispo Albert de Mainz, e só se lança ao cerco da cidade após ter garantido a conquista das terras que a rodeavam. Ainda a presença de um grandioso exército junto a Frederico, fato que não é mencionado por Otto no cerco a Mouzon realizado pelo imperador sugere que o duque suabo era mais prudente e experiente na guerra. Fica evidente que o frisigense associa essa vantagem do Staufer às suas virtudes, e por isso na obra do bispo estas se encontram colocadas anteriormente à narrativa da guerra.

Tal comparação não estaria completa, entretanto, se pudéssemos supor que Mouzon era uma fortaleza mais bem preparada para um cerco que Mainz. A descrição que o bispo frisigense faz da fortificação do conde Rainald aponta esta como muito bem localizada e de muito difícil acesso. Para evitar que se possa por em questão o cerco de Frederico II a Mainz, Otto de Freising faz também uma descrição da cidade, mostrando que esta era muito bem guarnecida por uma vasta muralha, repleta de torres, por um lado, e protegida pelo Reno de outro lado. Otto enfatiza que "Est autem predicta civitas magna e fortis" (OTTO in: WAITZ: 1912, p. 28).

\footnotetext{
${ }^{6}$ Otto de Freising se refere à Gália e aos gauleses ao tratar do território a oeste do Reno. Não podemos, entretanto, confundir com a Gália conquistada por Júlio César na Antigüidade, pois, embora a referência levantada pelo cronista seja aquela, o território ao qual o frisigense se refere não corresponde, senão em parte, àquele da Antigüidade.
} 
A postura de Frederico II diante do cerco também se distingue muito daquela de Henrique V. O imperador, após fracassar sua tentativa de conquista sobre a fortaleza de Mouzon, tenta conseguir a rendição da mesma ameaçando enforcar o conde diante dos portões da mesma. Trata-se de uma ação reprovável para um imperador romano, como o ideal de Otto propõe, pois evidencia uma falta de caráter dele. Já no caso oposto, de Frederico, o Caolho, o duque é chamado nobilissimus, pois teme que a plebe ${ }^{7}$, tomada pelo furor da batalha, venha a destruir os locais santos da cidade ${ }^{8}$, o que era sinal, segundo Otto de Freising, da fides - em seu sentido religioso - de Frederico.

$\mathrm{O}$ evento que se segue é talvez um dos mais significativos de todo o trecho a respeito do reinado de Henrique V. Trata-se da traição de Albert de Mainz e como Frederico II reagiu em tal situação. Escreve Otto:

Episcopus solutam obsidionem, dimissum cernens exercitum, apertis portis, cum magna ducem insequens milicia ex inproviso invadit. Dux cum suis, quos adhuc de tanto exercitu residuoshabebat, tunc primo dolum sentiendo, non, ut assolet arma ex inproviso corripientibus accidere, mente turbatus, sed ex presentia hostium amplius ad virtutemanimatus, arma sumit in hostemque ruit; viriliterque pugnatibus Alemannis, tandem ex parte Francorum comes Emicho, qui caeterorum primipilarius erat, letali sauciatus vulnere occubuit. Qua de re fracti animo Franci terga verterunt presidioque fugae se committunt. Quos fortissimus dux insecutus, occisis plurimis et captis, reliquos usque ad portas civitatis cum episcopo suo triumpho potitus fugavit. (OTTO in: WAITZ: 1912, p. 29).

É notória a diferença do resultado que Otto de Freising atribui às ações do degenerado Henrique $\mathrm{V}$ e do virtuoso Frederico II. O imperador, irado, procura vingar seu fracasso eliminando o conde Rainald, e, dissuadido de sua intenção primeira, é forçado a desistir do cerco, levando consigo, além da derrota, o conde

\footnotetext{
${ }^{7}$ Otto escreve aqui plebe para referir-se aos guerreiros não regulares. Aqueles que não são cavaleiros e que lutam a pé. Por toda a obra o cronista chama-os de plebes.

${ }^{8}$ OTTO in: WAITZ: 1912, p. 28
} 
prisioneiro. O Staufer, do contrário, crendo ter encontrado uma saída diplomática para o conflito, desiste do cerco - o que reforça a idéia de que o homem virtuoso de Otto de Freising é um pacificador, e embora seja um optimus na guerra, ele o é por amar a paz e fazer somente a guerra justa. Traído, entretanto, em seu desejo por paz, Frederico II é perseguido por Albert de Mainz e seu aliado, o conde Emico de Leiningen 9 , e se vê forçado a lutar, em meio à sua retirada. O providencialismo está novamente, na pena de Otto de Freising, ao lado do cavaleiro virtuoso, que mesmo despreparado para a situação de combate e em menor número que as tropas do arcebispo, mantém sua posição, contra-ataca seus inimigos e os vence. Toda a imagem criada em torno dessa batalha é cheia de uma simbologia muito própria do cronista em sua contrução de um ideal imperial. Vamos além, e afirmamos que se assemelha a um espelho de príncipe ${ }^{10}$, ao fazer do cavaleiro virtuoso - neste caso o pai do imperador Barbarossa - o modelo ideal de governante para o Império. A presença de Frederico II não somente se transforma em inspiração de virtude para os cavaleiros que se retiravam do cerco e retornam para enfrentar o inimigo traidor, mas vai além e põe-se como espelho para o governante ideal, monarca, duque ou outro senhor feudal, que pretende alcançar o favor divino para o sucesso nas armas e na política.

Por fim, gostaríamos de ressaltar o fato de que o cronista usa a palavra triumpho para indicar a vitória de Frederico II sobre o arcebispo de Mainz. Sem dúvida a escolha dessa palavra busca associar a imagem do duque suabo à dos grandes generais romanos. $\mathrm{O}$ termo refere-se mais que à vitória em si, para a qual havia o termo latino victoria, mas à conquista completa, à demontração da sunjugação do inimigo, e era o coroar das campanhas vitoriosas. Arriscamos afirmar que assim como os triunfos dos generais romanos da República precederam a glória dos Augustos, Otto pode

\footnotetext{
${ }^{9}$ MIEROW: 1953 , p. 46, nota 78 .

${ }^{10}$ Sobre os espelhos de príncipe ver MIETHKE: [s.d]. e SOUZA: 1997.
} 
estar apontando que o triunfo dos Staufer no ducado da Suábia era um prelúdio de sua ascensão à condição de Augusti.

Otto conclui sua narrativa a respeito das virtudes de Frederico II sob o reinado de Henrique V escrevendo que:

Quid plura? Pretaxatus dux, ut breviter dicam, per omnia patrem induens, tam fidus principi miles, tam utilis avunculo amicus extitit, ut sua virtute honorem regni labe factatum viriliter contra hostes decertando tam diu sustentaret, donec membra a capite suo dissidentia ad gratiam principis veniendo ad cor redirent. (OTTO in: WAITZ: 1912, p. 30).

O cronista mostra, em último lugar, como o cumprimento da comissão recebida por Hnerique IV, dentro de uma perspectiva das virtudes cristãs, levou Frederico II a promover a reconciliação entre o imperador e os príncipes, e como essa postura virtuosa trouxe o Império novamente à paz, pela restauração da sua honra.

\section{BIBLIOGRAFIA}

ARNOLD, Benjamin. German Knighthood 1050-1300. New York: Oxford University Press. 1985.

. Power and Property in Medieval Germany. New York: Oxford University Press. 2004

. Princes and Territories in Medieval Germany. New York: Cambridge University Press. 2003.

BAGGE, Sverre. Ideas and narrative in Otto of Freising's Gesta Friderici. Journal of Medieval History. Vol. 22, n. 4. 1996. pp. 345377.

BARBER, Malcolm. The Two Cities: Medieval Europe 1050-1320. New York: Routledge. 1993.

BLOCH, Marc. A sociedade feudal. Lisboa: Edições 70. 1982.

BURNS, J. H. (org) The Cambridge History of Medieval Political Thought c.350 - c.1450. Edinburg: Cambridge University Press. 2005. 
CARDINI, Franco. Barbarroja: vida triunfos e ilusiones de un emperador medieval. Barcelona: Península. 1987.

DUBY, Georges. As três ordens ou o imagináario do feudalismo. Lisboa: Estampa. 1982.

FERNANDES, Fátima Regina. O conceito de Império no pensamento político Tardo-Medieval. Separata de: FACETAS DO IMPÉRIO NA HISTÓRIA, 2006, Curitiba.

FOLZ, Robert. The concept of empire in western Europe: from the fifth to the fourteenth century. Londres: Edward Arnold. Trad. Sheila Ann Ogilvie. 1969.

FOURQUIN, Guy. Senhorio e feudalidade na Idade Média. Lisboa: Edições 70. Trad. Fátima Martins Pereira. 1987.

FRIGHETTO, Renan. Cultura e poder na Antigüidade Tardia ocidental. Curitiba: Juruá. 2000.

FUHRMANN, Horst. Germany in the high middle ages: c. 10501200. Cambridge: University Press. 2001.

GIERKE, Otto v. Political theories of the Middle Age. Cambridge: University Press. Trad. Frederic William Maitland. 1900.

GOETZ, Hans-Werner. "Gespaltene Gesellschaft" und Einheitsideal. Bemerkungen zum Gegenwartsbild Ottos von Freising. Zeitschrift für bayerische Kirchengeschichte. n. 50, 1981, pp. 14-21.

Geschichtsbewusstsein und Frühscholastik in der spätsalischen und frühstaufischen Weltchronistik. In: JARNUT, Jörg, e WEMHOFF, Matthias (orgs.). Vom Umbruch zur Erneuerung? Das 11. Und beginnende 12. Jahrhundert - Positionen der Forschung. Munique: Wilhelm Fink Verlag. 2006. pp. 197-218.

HEER, Friedrich. Das Heilige Römische Reich: von Otto dem Großen bis zur Habsburgischen Monarchie. Munique: Wilhelm Heyne. 1977.

LE GOFF, J. \& SCHMITT, Jean-Claude. Dicionário Temático do Ocidente Medieval. Bauru, SP: EDUSC. 2006.

LE GOFF, Jacques. Os intelectuais na Idade Média. Rio de Janeiro: José Olympio. 2006. 
LUSCOMBE, David e RILEY-SMITH, Jonathan. The New Cambridge Medieval History. Edimburgo: Cambridge University Press. 2 vol. 2004.

MIETHKE, Jürgen. Las ideas políticas de La Edad Media. Buenos Aires: Biblos. 1993.

NIETO SORIA, José Manuel. El Imperio medieval como poder público: problemas de aproximación a un mito político. Anales de la XXIII Semana de Estudios Medievales de Estella. [s.l./s.d.]. pp. 403 -440 .

OTTO. In: WAITZ, Georg. Ottonis et Rahewini gesta Friderici I. imperatoris. Hannover: Hahnsche Buchhandlung. 1912 (1997).

OTTO OF FREISING. The deeds of Frerderick Barbarossa. New York: Columbia University Press. 1953.

SOUZA, José Antônio de C. R. de e BARBOSA, João Morais. $O$ reino de Deus e o reindo dos homens: as relações entre os poderes espiritual e temporal na Baixa Idade Média (da Reforma Gregoriana a João Quidort). Porto Alegre: EDIPUCRS. 1997.

ULLMANN, Walter. A history of political thought: the middle ages. Harmondsworth: England. 1970. 